\title{
Article
}

\section{High Resolution Sentinel-2 Images for Improved Bathymetric Mapping of Coastal and Lake Environments}

\author{
Ali P Yunus ${ }^{1, *}$, Jie Dou ${ }^{2, *}$, Xuan Song ${ }^{3}$ and Ram Avtar ${ }^{4}$ \\ 1 The State Key Laboratory of Geohazard Prevention and Geoenvironment Protection (SKLGP), Chengdu \\ University of Technology, Chengdu, China \\ 2 Public Work Research Institute, Tsukuba, Japan \\ 3 Center for Spatial Information Science, The University of Tokyo, Japan; songxuan@csis.u-tokyo.ac.jp \\ 4 Faculty of Environmental Earth Science, Hokkaido University, Japan; ram@ees.hokudai.ac.jp \\ * Correspondence: yunusp@csis.u-tokyo.ac.jp (A.P.Y.); douj888@gmail.com (J.D.)
}

\begin{abstract}
Bathymetry of nearshore coastal environments and lakes are constantly reworking because of the change in the patterns of energy dispersal and related sediment transport pathways. Therefore, updated and accurate bathymetric models are a crucial component in providing basic information for scientific, managerial, and geographical studies. Recent advances in satellite technology have revolutionized the acquisition of bathymetric profiles, offering new vistas in mapping. This contribution analyzed the suitability of high resolution Sentinel-2 images for bathymetric mapping of coastal and lake environments. The bathymetric algorithm for satellite imageries was developed based on the available high resolution bathymetric data for Mobile Bay, Tampa Bay and Lake Huron regions obtained from National Oceanic and Atmospheric Administration (NOAA) National Geophysical Data Center (NGDC). The results demonstrate that the satellite derived bathymetry is efficient for retrieving depths up to $10 \mathrm{~m}$ for coastal regions and up to $30 \mathrm{~m}$ for lake environment. The root mean square error (RMSE) varies between $1.99 \mathrm{~m}$ and $2.80 \mathrm{~m}$ for the three regions. A comparison of Sentinel-2 derived bathymetry is also carried with the Landsat 8 OLI derived bathymetry. The results suggest Sentinel-2 images are capable of producing much accurate bathymetric maps than those from the Landsat 8 OLI images. Our work demonstrated that the freely available Sentinel-2 imagery proved to be a reliable method for acquiring updated high resolution bathymetric information for large areas in short span of time.
\end{abstract}

Keywords: Aquatic Environment, Remote Sensing, Topographic Mapping, Reflectance Spectra

\section{Introduction}

Aquatic environments are some of the dynamic regions of the earth. Among the aquatic systems, bathymetry or the depths of underwater terrain is one of the most important parameter that is constantly reworked and changing both in space and time. The rapid reworks in bathymetry are because of the change in the patterns of energy dispersal and related sediment transport pathways [1]. Clarke [2] studies indicated that huge turbidity currents cause's bedform migration within a few hours. Simons and Richardson, [3] studies observed positive correlation between bathymetric changes and measured stream power in fluvial systems. Sea level rise, shoreline morphology dynamics, beach nourishment, coastal erosion and accretion are other relevant forcing factors behind bathymetric changes. In shallower waters, updated and detailed coastal topography and bathymetry are critical for navigational purpose, pipeline constriction, exploration, defense and research applications and other management and spatial planning developmental projects [4,5]. However, due to the constant rework of bathymetry, mapping and measuring of these alterations requires a shift from static management measures to near real-time management procedures [6]. 
Traditional or static methods for monitoring and measuring bathymetry rely on field surveys utilizing echo sounding and mapping using multi-beam and side scan sonar. However, such approaches are characterized as being costly, labor-intensive and time-consuming techniques. In single beam echo sounders, a sound pulse from the vessel carrying the echo sounder instrument is sending underneath and listening until the echo from the bottom is heard, thus end up in providing depth at a single point. The water depth is then estimated by dividing the speed of sound by half of the time it takes for the echo to be heard. The multi-beam and side scan sonars transmits multiple beam of sound which represent the intensity and amplitude of reflected acoustic signals from the sea floor resulting in an image of its physical reflectance and scattering characteristics. Although multibeam echo sounding (MBES) surveys produce accurate bathymetric information of surveyed area, this method is constrained by spatial and temporal scale, expensive to operate, inability to survey in shallow seas, and marine protected areas [7,8]. It is estimated that the best resolution of MBES, more than 200 ship-years and billions of dollars would take to complete a swath survey of the sea floor [9]. Thus, the current bathymetric charts from ship-based surveys are inadequate for site specific application because only a small fraction of the aquatic environments has been surveyed.

An increasing body of contemporary literature shows the potential of remotely sensed data in bathymetric studies [10-13]. The major motivation for the usage of satellite in bathymetric surveys is that their uniform and comprehensive global coverage that can contribute to a better understanding of the topographic changes instantaneously and spatially. Radar altimeters abroad the spacecraft ERS-1 and Geosat have surveyed over global seas to obtain a high accuracy and moderate spatial resolution bathymetric information [14]. Dixon and Naraghi, [15] work summarizes the principles of satellite altimeter measurements for predicting seafloor topography. The gravity anomalies estimated from geoid undulations are highly correlated with seafloor topography, and these anomalies helps in mapping bathymetry with a radar altimeter. ERS-1 completed its near global mapping of sea surface topography in 1995, which was then used to reproduce the seafloor topography for data constrained and deeper oceans [16]. Because radar altimeter uses gravity anomaly to correlate bathymetry, this method is largely applicable for deep sea regions for mapping large sea mounts and guyots [17]. Furthermore, the estimation of bathymetry from gravity anomaly includes a number of mathematical models and thus is a complicated approach. On other hand, airborne LiDAR bathymetry (ALB) is a useful technique for measuring the moderately to shallower deep coastal waters and lakes (30 m - 50 m depth) from a low-altitude aircraft using a scanning, pulsed laser beam [18]. LiDAR offers about $70 \%$ reduction in operating costs when compared with standard ship surveys [18], however is again having spatial and temporal constraints. Satellite LiDAR (e.g., ICESat) have also been used to estimate water depth in clear waters with high accuracy in conjunction with Spectro-Radiometers and other remote sensing data [19,20].

Multispectral remote sensing datasets that are characterized with high spatial and temporal resolutions is the most frequently used method to estimate bathymetry on shallow water bodies such as coastal areas, estuaries, rivers and lakes [5,21]. Optical data approximates the radiative transfer in water using an empirical approach to model reflectance and measured bathymetry via least square regression analysis [22]. The present work explores the suitability of Sentinel-2 for retrieval of bathymetry of shallow coastal areas and lakes, and comparison with Landsat 8 OLI aiming to provide a new algorithm for obtaining and updating bathymetry which is under continual reworking processes.

\section{Materials and Methods}

\subsection{Study area}

United States (US) provides an excellent case study for the development of a systematic bathymetric retrieval approach. The governmental policy of full and open sharing, availability of high resolution dataset and archiving services give researchers the opportunity to initiate projects 
with confidence. Based on availability of high resolution bathymetric dataset, we chose three study area in the conterminous United States. They are: i) Mobile Bay, Mississippi, ii) area adjoining Tamba Bay and iii) Lake Huron (Figure 1).

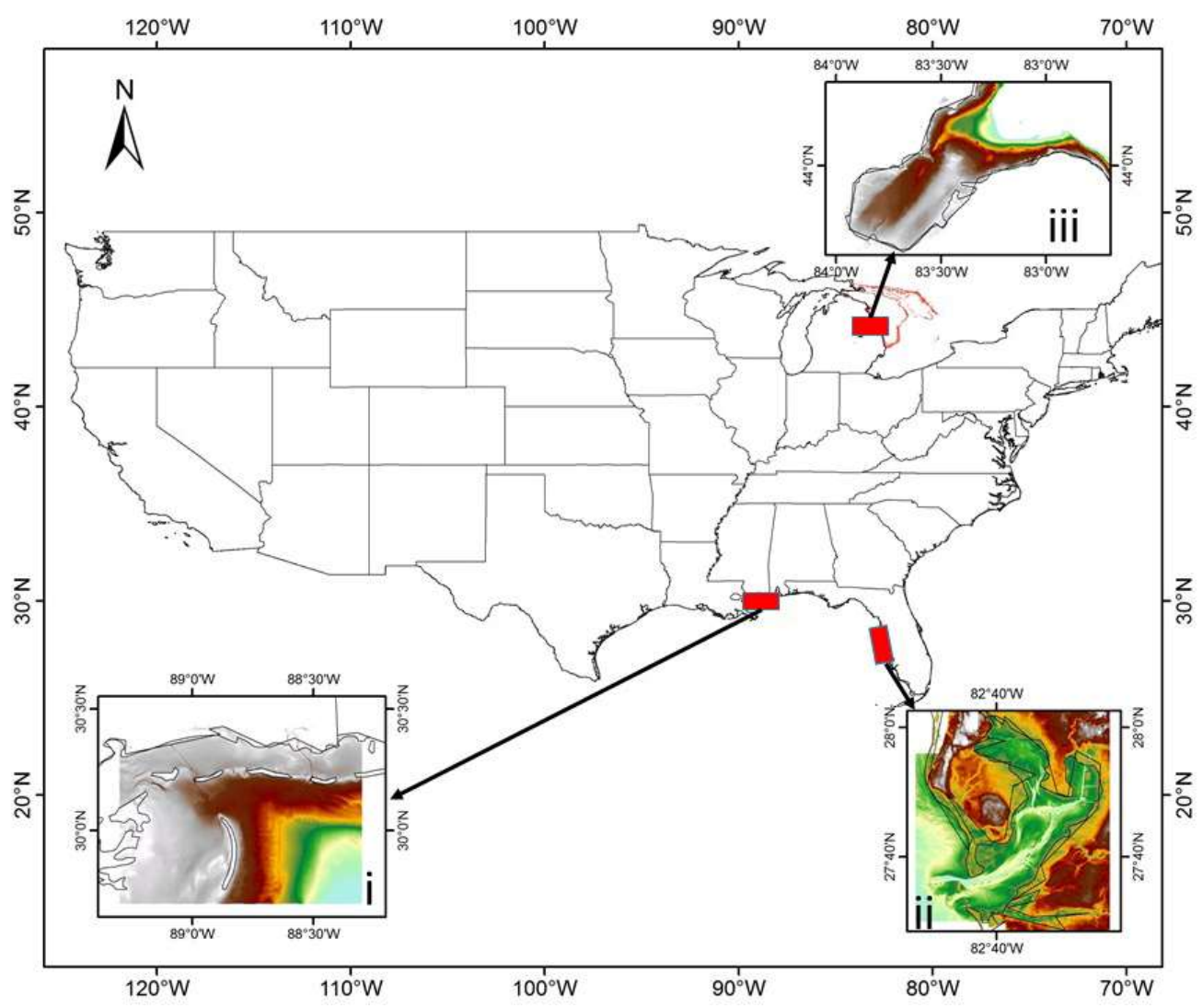

Figure 1. Location of study area: i) Mobile Bay, Mississippi, ii) area adjoining Tampa Bay, and iii) Lake Huron.

\subsection{Dataset}

\subsubsection{Satellite multispectral images}

The study takes advantage of using Landsat 8 Operational Land Imager (OLI) and Sentinal-2A Multi-Spectral Imager (MSI), that are currently the best freely available multispectral datasets. Landsat 8 OLI was launched in February 2013 as a successor to Landsat 5 and 7 mission. The OLI is superior to Landsat Thematic Mapper (TM) and Enhanced Thematic Mapper Plus (ETM+) with the incremental improvements in satellite, sensor, transmission, reception, data processing, and data distribution technologies [23]. The temporal resolution of OLI is 16 days. Compared with ETM+, the OLI spectral bands remain similar except two additional bands in blue and shortwave infrared spectrum. The key features of all the eleven Landsat 8 bands are summarized in Table 1. Sentinel-2A MSI was launched in June 2015 from French Guiana as a part of European Copernicus programme, designed by Airbus Defence and Space for the European Space Agency (ESA). The Sentinel MSI offers a high temporal resolution of 5 days at the equator compared to the 16 days of Landsat 8 OLI. This sensor has 13 spectral bands covering the visible, near infrared and shortwave infrared part of the electromagnetic spectrum. The swath width of Sentinel-2 is $290 \mathrm{~km}$ as compared to $185 \mathrm{~km}$ of Landsat 8. Table 1 shows the key summary of 13 spectral bands of MSI sensor. The geometrically corrected Landsat 8 OLI and Sentinel-2A MSI data are available via www.earthexplorer.gov as Level-1T (L1T) top-of-atmosphere (TOA) reflectance images and Level-1C (L1C) TOA reflectance tiles in the 
Worldwide Reference System (WRS-2) path/row coordinate system, is used in this study. Cloud free dataset one each for the three study sites are downloaded for both the Sentinel-2 MSI and Landsat-8 OLI sensor. Date of acquisition and path, row/tiles details are also presented in Table 1.

Table 1. Key summary of Landsat 8 Operational Land Imager (OLI) and Sentinal-2A MultiSpectral Imager (MSI) spectral bands, and date of acquisition, path, row / tiles details of images used in this study.

\begin{tabular}{|c|c|c|c|c|c|c|c|}
\hline \multicolumn{4}{|c|}{ Landsat 8 OLI } & \multicolumn{4}{|c|}{ Sentinel-2 MSI } \\
\hline Band & \multirow{2}{*}{$\begin{array}{c}\text { Central } \\
\text { Wavelength } \\
(\mathrm{nm})\end{array}$} & Band & Resolution & Band & Central & Band & Resolution \\
\hline No. & & $\begin{array}{l}\text { Width } \\
(\mathrm{nm})\end{array}$ & $(\mathrm{m})$ & No & $\begin{array}{c}\text { Wavelength } \\
(\mathrm{nm})\end{array}$ & $\begin{array}{l}\text { Width } \\
(\mathrm{nm})\end{array}$ & $(\mathrm{m})$ \\
\hline 1 & 442 & 15 & 30 & 1 & 443 & 20 & 60 \\
\hline 2 & 482 & 60 & 30 & 2 & 490 & 65 & 10 \\
\hline 3 & 561 & 57 & 30 & 3 & 560 & 35 & 10 \\
\hline 4 & 654 & 37 & 30 & 4 & 665 & 30 & 10 \\
\hline 5 & 864 & 28 & 30 & 5 & 705 & 15 & 20 \\
\hline 6 & 1608 & 84 & 30 & 6 & 740 & 15 & 20 \\
\hline 7 & 2200 & 186 & 30 & 7 & 783 & 20 & 20 \\
\hline 8 & 589 & 172 & 15 & 8 & 842 & 115 & 10 \\
\hline 9 & 1373 & 20 & 30 & $8 b$ & 865 & 20 & 20 \\
\hline 10 & 1089 & 59 & 100 & 9 & 945 & 20 & 60 \\
\hline \multirow[t]{3}{*}{11} & 1200 & 101 & 100 & 10 & 1380 & 30 & 60 \\
\hline & & & & 11 & 1610 & 90 & 20 \\
\hline & & & & 12 & 2190 & 180 & 20 \\
\hline \multicolumn{8}{|c|}{ Date of acquisition L8 OLI and S2 MSI Scenes } \\
\hline \multicolumn{2}{|c|}{ Mobile Bay: } & \multicolumn{2}{|c|}{ R/23 Path 21 Row 39} & \multicolumn{3}{|c|}{ 2016/JAN/04 Tile No. T16RCU } & \\
\hline Lake Huron & $\begin{array}{l}2015 / F \\
2016 / A\end{array}$ & \multicolumn{2}{|c|}{ 2015/FEB/20 Path 17 Row 41} & \multicolumn{3}{|c|}{ 2016/FEB/14 Tile No. T17RLL } & \\
\hline
\end{tabular}

\subsubsection{Bathymetric data}

The Mobile Bay bathymetric dataset (Biloxi DEM) was developed by the National Geophysical Data Center (NGDC), an office of the National Oceanic and Atmospheric Administration (NOAA) in March 2007. Bathymetric datasets used in the compilation of the Biloxi DEM include 48 NOS hydrographic surveys, 25 USACE surveys of dredged shipping channels, and OCS ENC extracted soundings in the Chandeleur Sound region. Tampa Bay bathymetric DEM compilation are result of extensive collaboration between NOAA; the U.S. Geological Survey (USGS); and other agencies such as federal and private companies. Bathymetry of Lake Huron has been compiled as a component of a NOAA project to rescue Great Lakes lake floor geological and geophysical data and make it more accessible. For this, bathymetric data are collected from US Army Corp. of Engineers, the NOAA National Ocean Service (NOS) and the Canadian Hydrographic Service. These three DEMs are downloaded via NOAA's National Geophysical Data Center (NGDC) http://www.ngdc.noaa.gov/. Each of them has been then resampled to $10 \mathrm{~m}$ and $30 \mathrm{~m}$ in order to match with Sentinel-2 and Landsat-8 native resolutions. 
5 of 19

\subsection{Empirical derived water depth}

The bathymetry retrieval from optical satellite remote sensing is based on the wavelengthdependent attenuation of light in the water column [5]. It is known that shallow water absorbs less energy than deep water and therefore will have higher reflectance of solar radiation and vice versa [24]. Further, in shallower waters solar radiation is reflected back to the surface after touching the bottom depth. This water leaving reflectance (Rrs) measured by the satellite sensor is then used to transform it to water depth by analytical equations. However, this assumption is expected to be valid only in shallow clear waters, because Rrs depends not only on the reflectance from bottom surface, but also on the absorption and scattering properties of dissolved and suspended material in the water column. The Rrs from different spectral wavelength bands of multispectral sensors (e.g. Landsat series, ASTER, RapidEye and QuickBird) have been implemented in previous studies to map bathymetry $[5,8,11,24]$. The blue and green wavelengths are considered to be very suitable in estimating bathymetry because reflectance between 400 and $600 \mathrm{~nm}$ have the greatest penetration though the water column [8].

In this study, we utilized the DN values of band 2 (blue) and band 3 (green) of both Landsat 8 OLI and Sentinal 2A MSI products (Landsat: band $2=482 \mathrm{~nm}$ and band $3=561 \mathrm{~nm}$; Sentinal: band 2 $=490 \mathrm{~nm}$ and band $3=560 \mathrm{~nm}$ ). For this, the Top of Atmosphere (ToA) OLI and MSI products are first atmospherically corrected for the effects of atmospheric gases and aerosols to yield surface spectral reflectance using dark object subtraction (DOS) method. In DOS method, we assume that the dark objects in an image reflect no light, and any value captured by satellite sensor are due to the atmospheric scattering [16]. The atmospheric scattering effect is then removed by subtracting the value captured in dark object pixel from every pixel in the band. The corrected surface reflectance data are then used for estimating the water depth.

Following Pacheco et al. [5], the band ratio of blue by green can provide satellite derived water depth by linear solution of water reflectance and bathymetric depth. This spectral band-ratio method employs an empirically derived formula to relate lake depths to the ratio of the reflectance of two spectral bands. To apply the multiple linear regression, the depth data points were extracted from bathymetric LiDAR for three different sites at exactly the same points as were the data retrieved by the Landsat 8 image and Sentinel OLCI images. The points for constructing linear model are randomly selected based on the size of the available images and DEM; 6000 for Mobile Bay, 3000 for Tampa Bay, and 1000 for Lake Huron. A limitation of this comparison is the fact that the bathymetric depth dataset used are dated much older than the L8 and OLCI scenes. Therefore, a perfect agreement between SDB and surveyed maps is not expected, given that morphological differences are likely to occur in a moderately energetic nearshore system comprising barrier islands and tidal inlets exposed to dynamic oceanographic conditions. 


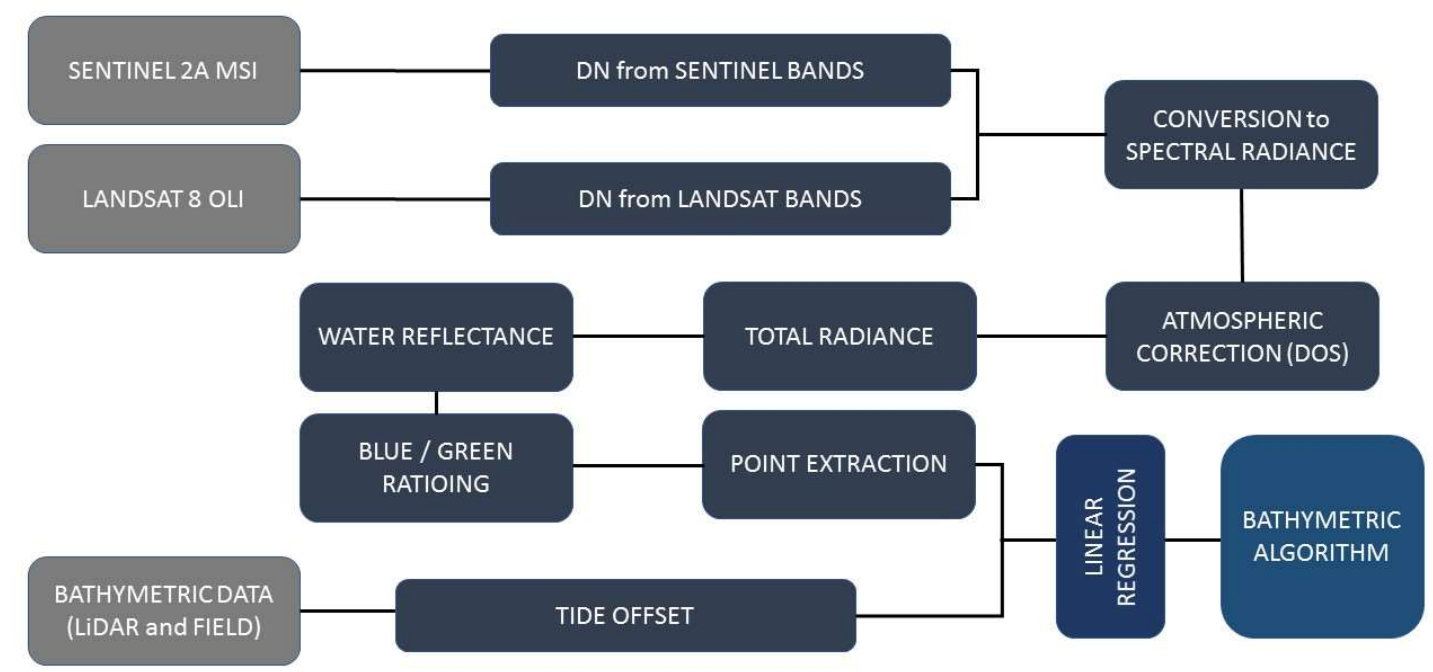

Figure 2. Flowchart for deriving Bathymetric maps from Sentinel-2 MSI and Landsat 8 OLI images.

\section{Results and Discussions}

\subsection{Site Specific Bathymetric Algorithm (Mobile Bay)}

T After generating the B/G model for both S2 MSI and L8 OLI satellite images, six-thousand random point values were extracted from both the ratioed image and bathymetric DEM at the same place. Linear regression model is then applied to these extracted values after filtering (Figure 3). Figure $3 \mathrm{a}$ and $3 \mathrm{~b}$ shows the ratioed image versus surveyed bathymetric DEM linear regression model for S2 MSI and L8 OLI images respectively for a depth up to $30 \mathrm{~m}$. The r2 values obtained is (0.55) and (0.22) respectively for S2 and L8 images. It can be observed from the figure that after crossing a depth of roughly $10 \mathrm{~m}$, the B/G signals start scattering (Figure $3 \mathrm{a}$ and $3 \mathrm{~b}$ ). This suggests that the light penetration in the Bay is limited to $10 \mathrm{~m}$. After adjustment of the depth up to $10 \mathrm{~m}$ in the linear model, the $\mathrm{r} 2$ values increased significantly ( 0.90 and 0.89 for S2 and L8 respectively) (Figure 3c and 3d). This significant increase in the $\mathrm{r} 2$ values indicate that bathymetry of water bodies up to depth of $10 \mathrm{~m}$ could be derived from Sentinel and Landsat imageries.

The equation to derive depth from Sentinel-2 MSI for Mobile Bay area is follows:

$$
S d B=-52.51 \times\left(\operatorname{Rrs} \frac{B}{G}\right)+42.97
$$

The equation to derive depth from Landsat 8 OLI for Mobile Bay area is follows:4

$$
S d B=-36.45 \times\left(\operatorname{Rrs} \frac{B}{G}\right)+44.18
$$

where SdB is satellite derived bathymetry, and Rrs B/G is ratio of water leaving reflectance from Blue band and Green band. 

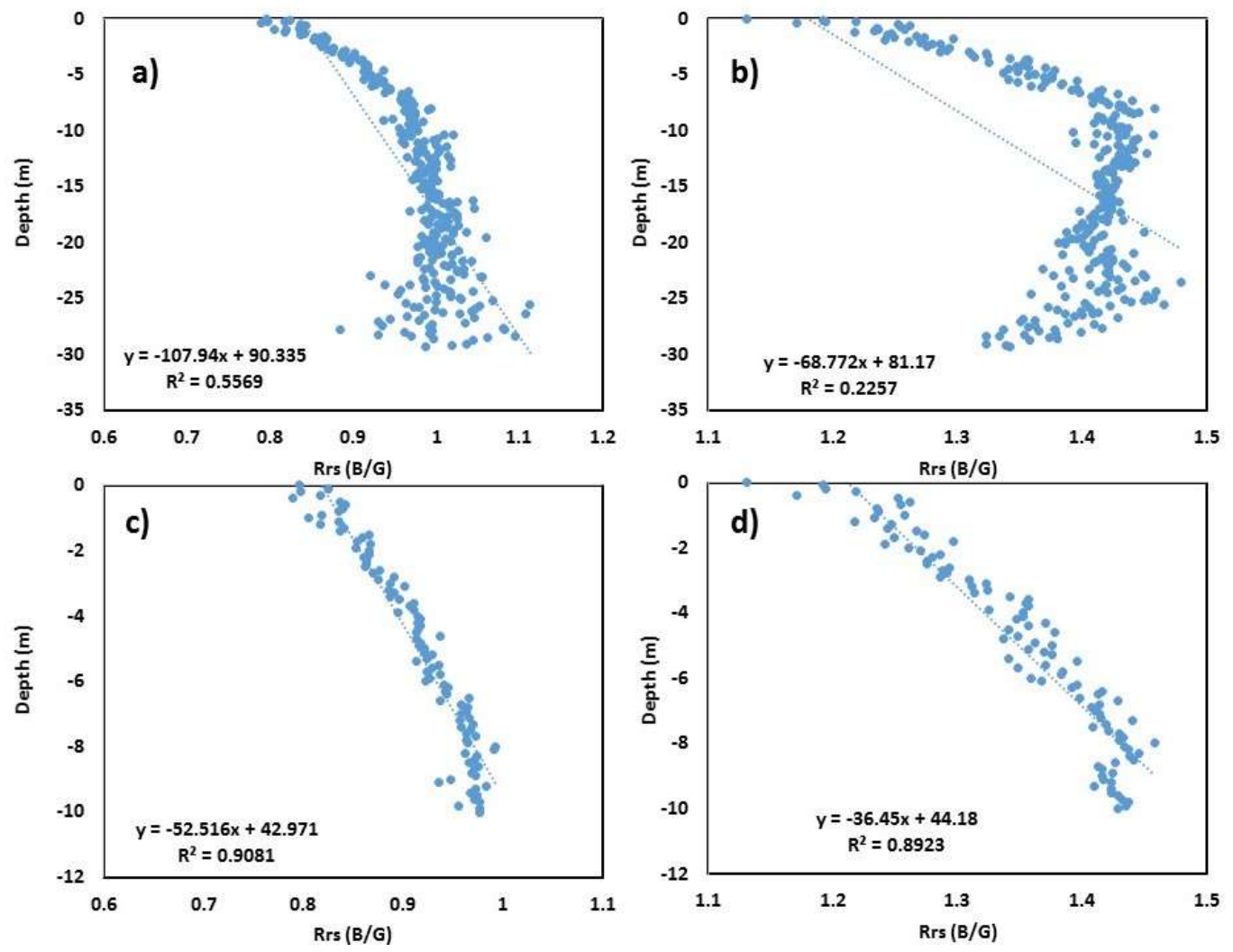

Figure 3. Scatter plot of blue/green (B/G) band versus surveyed depth for Mobile Bay; a) Sentinel 2 MSI B/G vs surveyed bathymetry up to $30 \mathrm{~m}$ depth, b) Landsat 8 OLI B/G vs surveyed bathymetry up to $30 \mathrm{~m}$ depth, c) Sentinel 2 MSI B/G vs surveyed bathymetry up to $10 \mathrm{~m}$ depth and d) Landsat 8 OLI B/G vs surveyed bathymetry up to $10 \mathrm{~m}$ depth.

\subsection{Site Specific Bathymetric Algorithm (Tampa Bay)}

For Tampa Bay, 3000 random points values were extracted from both the $B / G$ image and bathymetric DEM at the same place. Linear regression is then applied to the extracted values after averaging (Figure 4). Figure $4 \mathrm{a}$ and $4 \mathrm{~b}$ shows the ratioed image versus surveyed bathymetric DEM linear regression model for S2 MSI and L8 OLI images respectively for a depth up to $30 \mathrm{~m}$. The $\mathrm{r} 2$ values obtained is (0.05) and (0.28) respectively for S2 and L8 sensors. Similar to the Mobile Bay, it can be observed from the figure that after crossing a depth of roughly $13 \mathrm{~m}$, the B/G signals starts scattered (Figure 4a and $4 \mathrm{~b}$ ) indicating light penetration in the Bay is limited to $\sim 13 \mathrm{~m}$. After adjustment of the depth up to $10 \mathrm{~m}$ in the linear model, the $\mathrm{r} 2$ values increased significantly $(0.73$ and 0.85 for S2 and L8 respectively (Figure 4c and 4d).

The equation to derive depth from Sentinel-2 MSI for Tampa Bay area is follows:

$$
S d B=-102.81 \times\left(\operatorname{Rrs} \frac{B}{G}\right)+79.35
$$

The equation to derive depth from Landsat 8 OLI for Tampa Bay area is follows:

$$
S d B=-66.05 \times\left(\operatorname{RrS} \frac{B}{G}\right)+65.89
$$


8 of 19
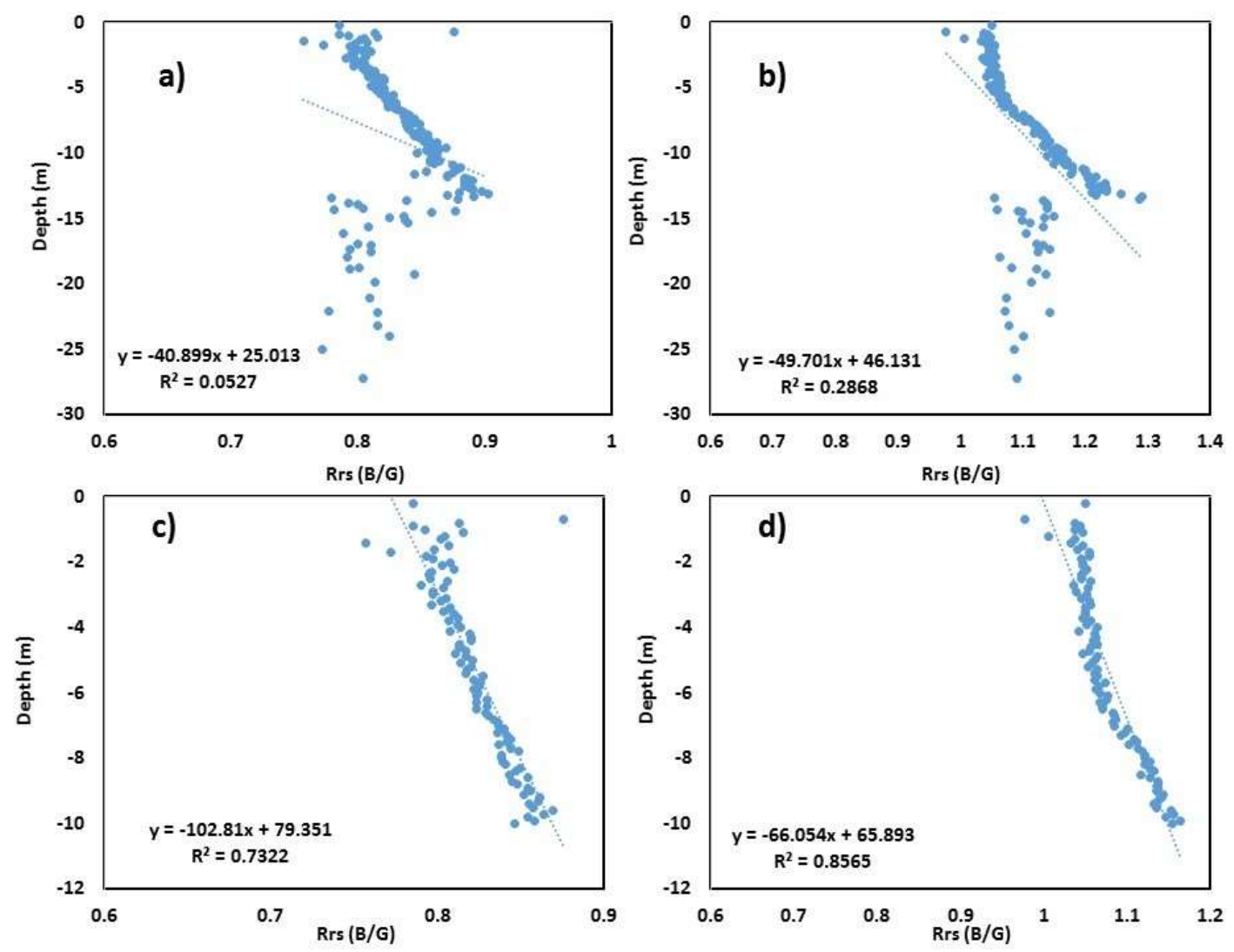

Figure 4. Scatter plot of blue/green (B/G) band versus surveyed depth for Tampa Bay; a) Sentinel 2 MSI B/G vs surveyed bathymetry up to $30 \mathrm{~m}$ depth, b) Landsat 8 OLI B/G vs surveyed bathymetry up to $30 \mathrm{~m}$ depth, c) Sentinel $2 \mathrm{MSI}$ B/G vs surveyed bathymetry up to $10 \mathrm{~m}$ depth and d) Landsat 8 OLI B/G vs surveyed bathymetry up to $10 \mathrm{~m}$ depth.

\subsection{Site Specific Bathymetric Algorithm (Lake Huron)}

The results obtained from Lake Huron is completely in contrast with the results from former two locations. The multiple linear model applied to the random point values extracted from $B / G$ band ratioed image and bathymetric DEM is shown in Figure 5. The $\mathrm{r} 2$ values obtained for $30 \mathrm{~m}$ depth is (0.92) and (0.67) respectively for S2 and L8 sensors (Figure 5a and 5b). Whereas the adjusted depth to $10 \mathrm{~m}$ shows a decrease in $\mathrm{r} 2$ value $(0.90$ and 0.58$)$ as shown in Figure $5 \mathrm{c}$ and $5 \mathrm{~d}$. The high value of $\mathrm{r} 2$ between the $\mathrm{B} / \mathrm{G}$ and bathymetry represented for $30 \mathrm{~m}$ clearly shows the penetration of light in deeper areas in optically clear waters such as lakes.

The equation to derive depth from Sentinel-2 MSI for Lake Huron is follows:

$$
S d B=-31.14 \times\left(\operatorname{Rrs} \frac{B}{G}\right)+17.49
$$

The equation to derive depth from Landsat 8 OLI for Lake Huron is follows:

$$
S d B=-36.29 \times\left(\operatorname{Rrs} \frac{B}{G}\right)+41.49
$$


9 of 19
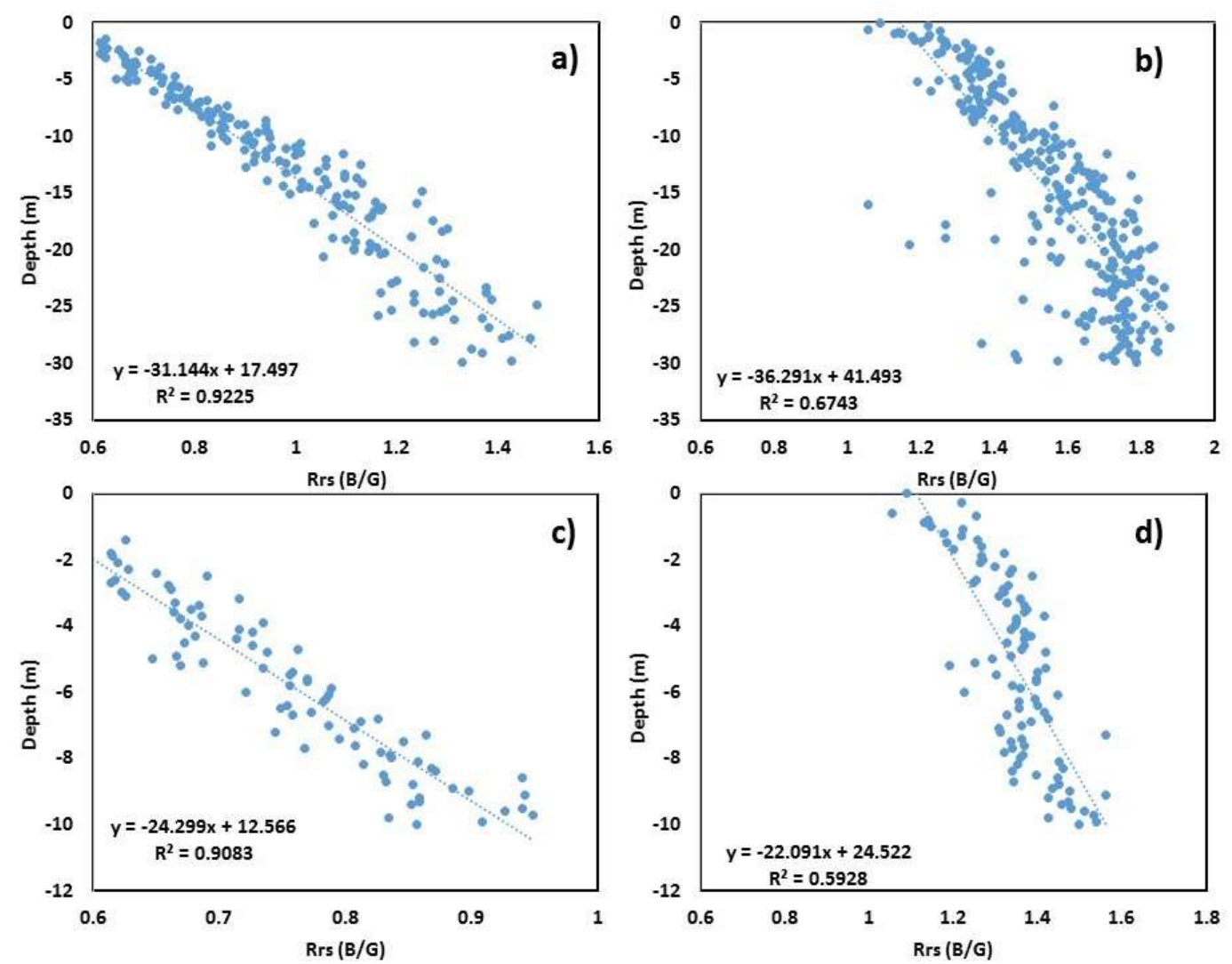

Figure 5. Scatter plot of blue/green $(\mathrm{B} / \mathrm{G})$ band versus surveyed depth for Lake Huron; a) Sentinel 2 MSI B/G vs surveyed bathymetry up to $30 \mathrm{~m}$ depth, b) Landsat 8 OLI B/G vs surveyed bathymetry up to $30 \mathrm{~m}$ depth, c) Sentinel $2 \mathrm{MSI} B / \mathrm{G}$ vs surveyed bathymetry up to $10 \mathrm{~m}$ depth and d) Landsat 8 OLI B/G vs surveyed bathymetry up to $10 \mathrm{~m}$ depth.

\subsection{S Combined Bathymetric Model}

After obtaining the site specific bathymetric model, the data from all the three study regions are integrated to develop the combined bathymetric algorithm in order to obtain the regional satellite derived bathymetry (Figure 6).

The equation to derive depth from Sentinel-2 MSI:

$$
S d B=-33.64 \times\left(\operatorname{Rrs} \frac{B}{G}\right)+21.84(7)
$$

The equation to derive depth from Landsat 8 OLI:

$$
S d B=-28.28 \times\left(\operatorname{Rrs} \frac{B}{G}\right)+29.14(8)
$$



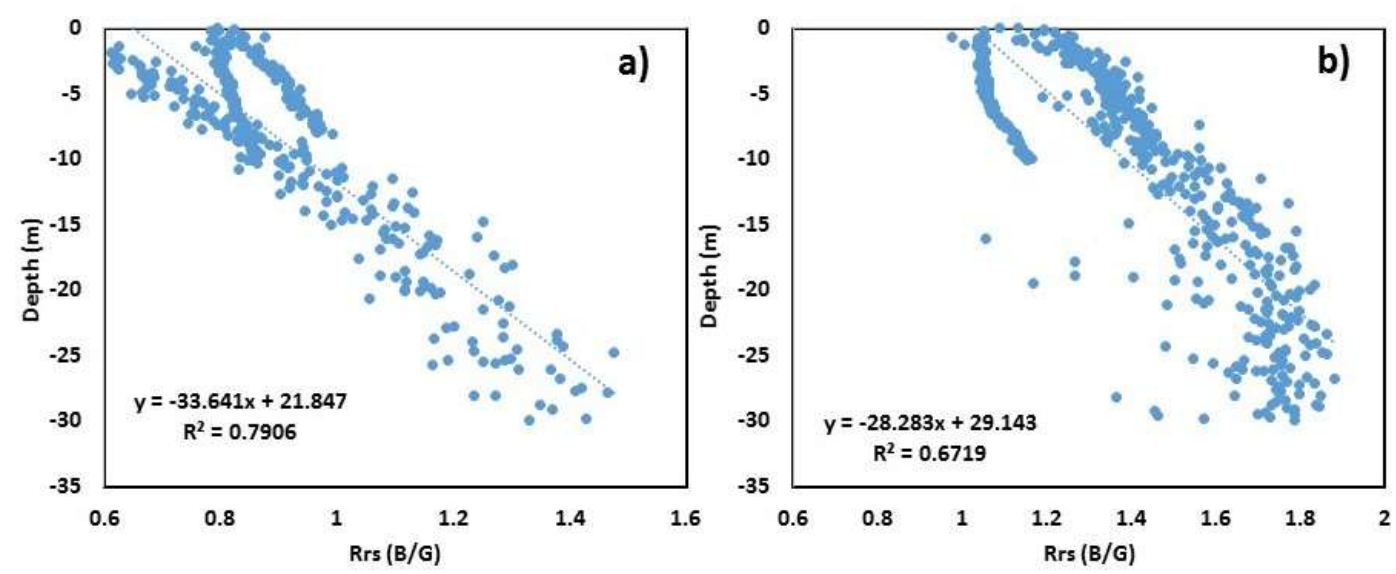

Figure 6. Scatter plot of blue/green $(B / G)$ band versus surveyed depth for all three study area; a) Sentinel 2 MSI B/G vs surveyed bathymetry up to $30 \mathrm{~m}$ depth, b) Landsat 8 OLI B/G vs surveyed bathymetry up to $30 \mathrm{~m}$ depth.

\subsection{Bathymetric Mapping}

Bathymetry for the three study regions are mapped using both the site-specific algorithm and the integrated model. The bathymetric map derived from Sentinel- 2 and Landsat 8 satellite imagery using water leaving reflectance from ratio of blue and green wavelengths are shown in Figure $7-9$. A $9 \times 9$ smoothening filter is applied to the final map for visual comparison. Given the difference in time of acquisition of bathymetric surveys and that of satellite image, the direct comparison could not yield a positive result. However, the root mean square error (RMSE), standard deviation $(\sigma)$, mean, maximum and minimum is calculated for the satellite derived bathymetry for assessment. Table 2 shows the results of statistical analysis.

The RMSEs estimated from the site-specific algorithm (SSA) for Mobile Bay using 2000 random depth values are 2.26, and 2.54 respectively for S2 and L8 images; whereas the same for integrated model (IM) are 4.84 and 5.18 respectively (Table 2). Since the RMSE estimated for integrated model for both the sensors are larger (4.18 and 5.18), they are not shown in maps. As observed, large differences occur in areas with depths of 2-4 $\mathrm{m}$ and 6-8 $\mathrm{m}$ (Fig. 8a). Up to $6 \mathrm{~m}$, S2 SSA algorithm overestimate the depth values and for depths more than $6 \mathrm{~m}$, vice versa ensues. Nevertheless, the satellite derived bathymetric maps are effective for representing the nearshore isobaths as well as the shapes of the bottom morphologies (Figure 7a).

For Tampa Bay the RMSEs estimated are 2.80, 2.62, 2.50 and 5.67 respectively for S2 SSA, S2 IM, L8 SSA and L8 IM. Two thousand random depth points are used for performing statistical analysis. As observed from the Figure $9 \mathrm{a}-9 \mathrm{c}$ and the statistical analysis, L8 SSA derived bathymetry have an edge over S2 images for this particular region (bias 0.24). Nevertheless, S2 images also produced a good representation of bottom topography with a bias of only $0.58 \mathrm{~m}$. This can also been seen from Figure 8b.

The bathymetric map produced for Lake Huron using S2 SSA found to be a close approximation of the actual bottom topography (Figure 10a-10c). The bias and RMSE estimated are 0.07 and 1.99 respectively for this model. The differences are concentrated in the $0-3 \mathrm{~m}$ class, near the southwestern region (Figure 7c). The other models show a RMSEs of 3.30, 4.74 and 5.07 respectively for S2 IM, L8 SSA and L8 IM. Again because of larger bias and RMSEs, the integrated model results are not shown in the maps. 
Table 2. Statistical analysis of satellite derived bathymetry.

\begin{tabular}{llllll}
\hline & \multicolumn{5}{c}{ Mobile Bay } \\
& Surveyed & S2 SSA & S2 IM & L8SSA & L8 IM \\
\hline RMSE & & 2.26 & 4.84 & 2.54 & 5.18 \\
MAX & -10.00 & -13.32 & -14.48 & -10.0 & -13.94 \\
MIN & 0.00 & 3.92 & 6.25 & -0.40 & 5.45 \\
MEAN & -4.58 & -5.51 & -9.21 & -5.39 & -9.28 \\
STD & 2.20 & 2.79 & 1.78 & 2.71 & 2.25 \\
BIAS & & 0.93 & 4.63 & 0.81 & 4.70 \\
& & & & & \\
\hline
\end{tabular}

\begin{tabular}{llllll}
\hline & \multicolumn{5}{c}{ Tampa Bay } \\
& Surveyed & S2 SSA & \multicolumn{1}{c}{ S2 IM } & \multicolumn{1}{c}{ L8SSA } & \multicolumn{1}{c}{ L8 IM } \\
\hline RMSE & & 2.80 & 2.62 & 2.50 & 5.67 \\
MAX & -29.63 & -32.63 & -14.80 & -19.87 & -7.58 \\
MIN & 0.00 & 10.36 & 3.93 & 4.09 & 2.68 \\
MEAN & -7.46 & -6.88 & -6.37 & -7.22 & -2.16 \\
STD & 2.82 & 3.25 & 1.06 & 3.73 & 1.59 \\
BIAS & & 0.58 & 1.09 & 0.24 & 5.30 \\
& & & & & \\
\hline
\end{tabular}

\begin{tabular}{llllll}
\hline & \multicolumn{5}{c}{ Lake Huron } \\
& Surveyed & \multicolumn{1}{c}{ S2 SSA } & \multicolumn{1}{c}{ S2 IM } & L8SSA & \multicolumn{1}{c}{ L8 IM } \\
\hline RMSE & & 1.99 & 3.30 & 4.74 & 5.07 \\
MAX & -30.00 & -30.20 & -29.68 & -22.21 & -20.50 \\
MIN & 0.00 & 6.42 & 9.87 & 10.59 & 5.06 \\
MEAN & -7.15 & -7.22 & -4.93 & -7.94 & -9.38 \\
STD & 5.95 & 6.28 & 6.78 & 5.45 & 4.25 \\
BIAS & & 0.07 & 2.22 & 0.79 & 2.23 \\
\hline
\end{tabular}



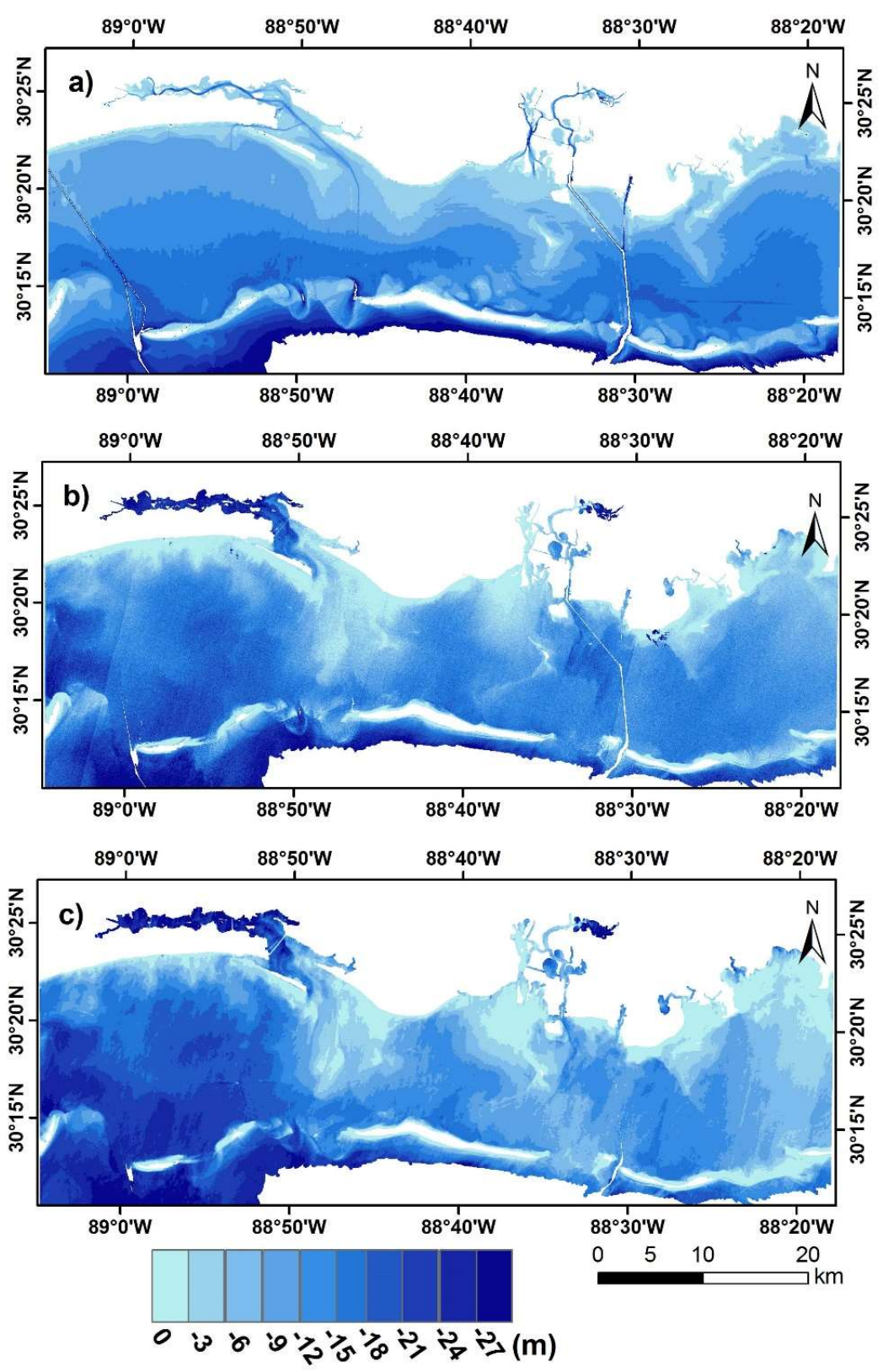

Figure 7. Bathymetric map of Mobile Bay, Missisippi. a) surveyed bathymetry, b) Sentinel-2 derived bathymetry and c) Landsat 8 OLI derived bathymetry from site specific algorithm. 

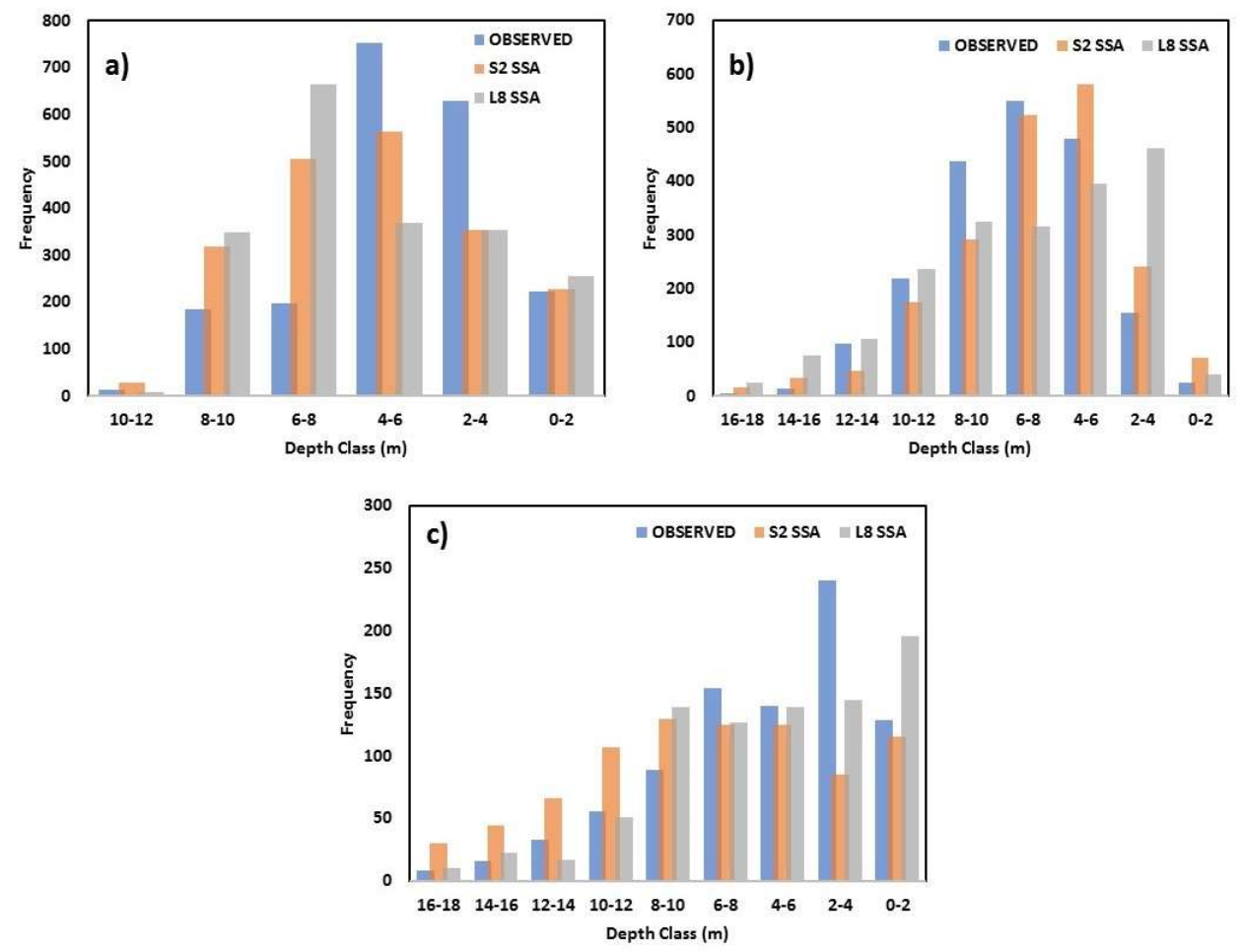

Figure 8. Histogram of depth classes for comparison between different bathymetric maps.
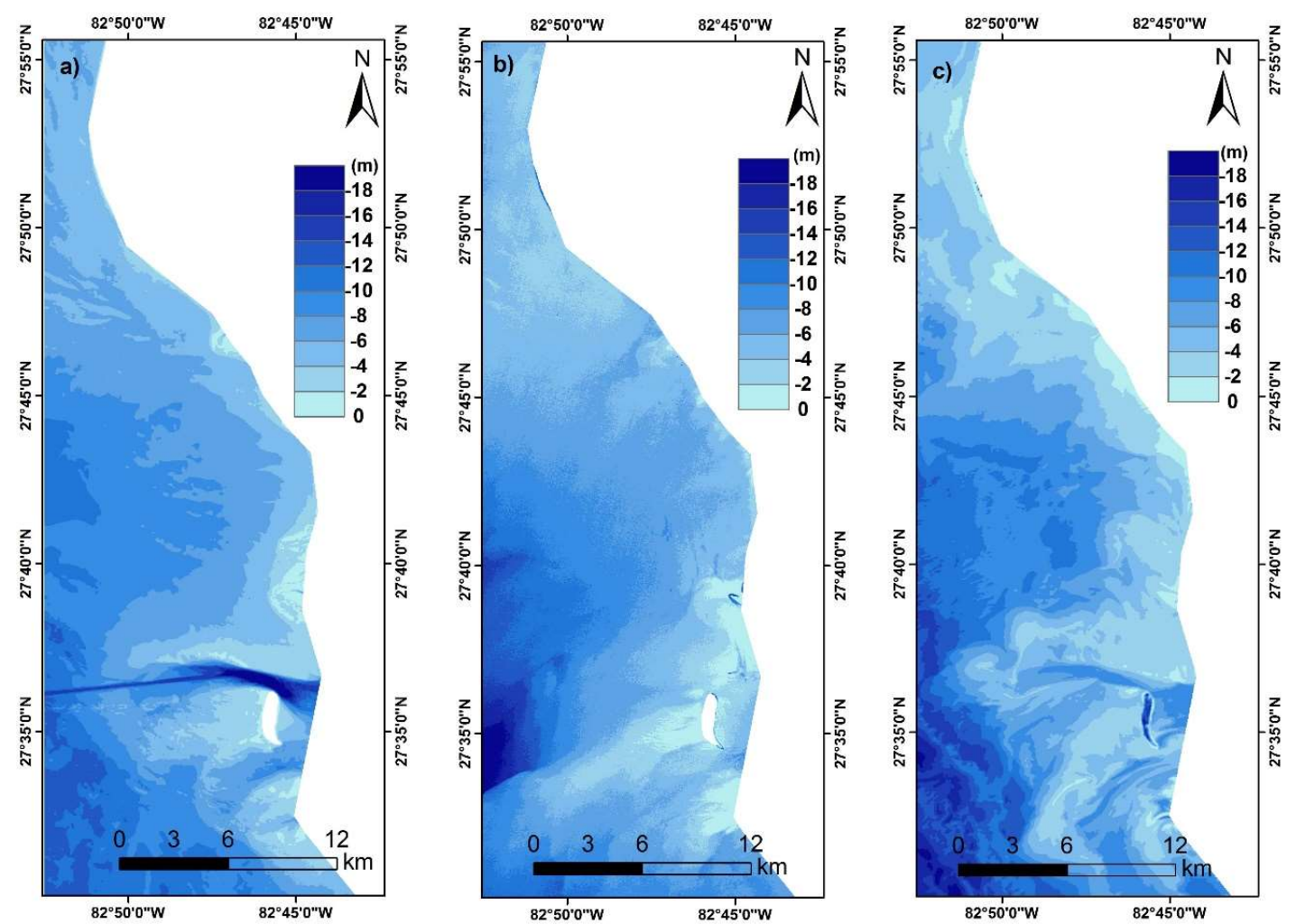

Figure 9. Bathymetric map of Tampa Bay a) surveyed bathymetry, b) Sentinel-2 derived bathymetry and c) Landsat 8 OLI derived bathymetry from site specific algorithm. 

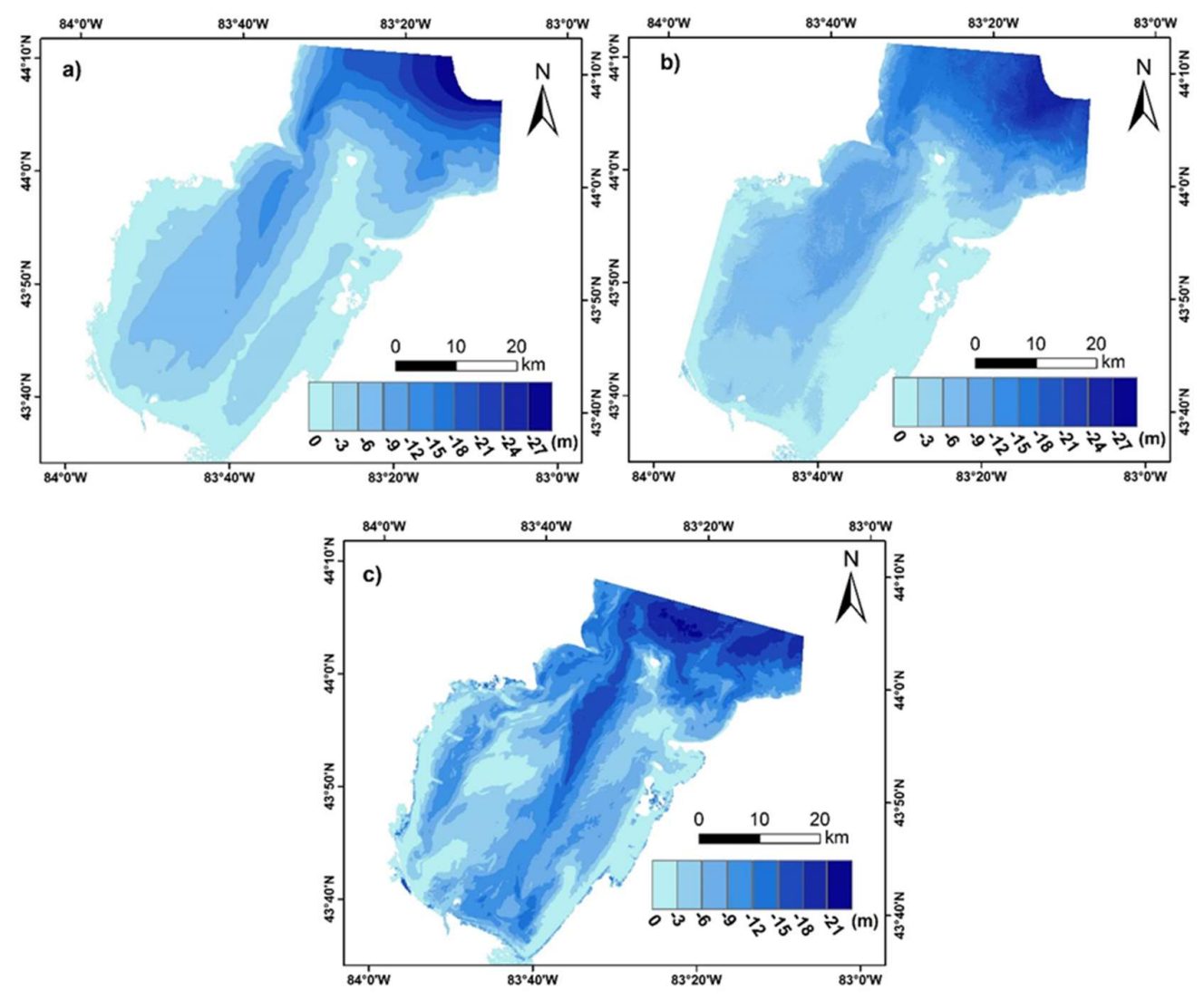

Figure 10. Bathymetric map of Lake Huron. a) surveyed bathymetry, b) Sentinel-2 derived bathymetry and c) Landsat 8 OLI derived bathymetry from site specific algorithm.

\subsection{Bathymetric profile analysis}

To do meaningful comparison of the observed bathymetry with the modeled bathymetry, longitudinal profile analysis is carried. Because the RMSEs estimated for integrated model are larger than expected, the profiles are extracted only from site specific algorithm derived topography. For this, using ESRI's ArcGIS we created line shapefiles for the study region perpendicular to the shoreline. Points along the line are then made at $90 \mathrm{~m}$ spacing. Finally, depth values are extracted for each point from the surveyed map, S2 SSA derived bathymetry and L8 SSA derived bathymetry. A $9 \times 9$ window averaging is applied to the S2 derived profiles for smoothening the profile. A total of 6 profiles are extracted for each of the study area (Figure 11 - Figure 13).

Figure 11 reports the six-representative bathymetric profile for Mobile Bay. Three of the studied bathymetric longitudinal profiles exhibit a decent match with the observed profile (Figure 11a, 11b and 11f). This is a good first indication that the Sentinel-2 can provide a reasonable estimate of the real bathymetry. These profiles have at worst $2 \mathrm{~m}$ differences in depth. The mean differences for these three profiles range from $0.25 \mathrm{~m}$ to $1 \mathrm{~m}$. Nevertheless, the other profiles shown in Figure 11c, 11d and $11 \mathrm{e}$ also follows the general trend of observed bathymetry at places but with a worst difference of $6.94 \mathrm{~m}$. Note that the mean differences for these three profiles is less than $1 \mathrm{~m}$ (Table 1A) indicating reasonable quantitative match. The differences observed for L8 derived profiles are found larger than that observed for S2 profiles. The worst case for L8 is $14.32 \mathrm{~m}$ difference with observed and mean varies from 0.64 to $4.26 \mathrm{~m}$ for all six profiles.

Bathymetric profiles derived for Tampa Bay are shown in Figure 12. Visual interpretation suggests there exists reasonable match of surveyed bathymetry with S2 SSA in profile 3 (Figure 12c), 
profile 5 (Figure 12d) and profile 6 (Figure 12). Quantification shows at worst case the difference is $2.95 \mathrm{~m}$ and mean difference of less than $1.28 \mathrm{~m}$ for these three profiles. Other profiles analysed shows higher difference with the surveyed one $(3.7 \mathrm{~m}$ to $6.21 \mathrm{~m})$ however with a mean difference ranging between $0.13 \mathrm{~m}$ and $1.75 \mathrm{~m}$ (Table 1B ). Similar to the Mobile Bay profiles, L8 SSA bathymetry for Tampa Bay also shows higher difference with original indicating improved retrieval from Sentinel sensors.

Accordance to what is observed in the RMSE analysis, visual comparison reveals all the six profiles for S2 SSA in Lake Huron shows a close match with the observed bathymetry (Figure 13). Quantification shows the mean difference is between 0.19 to $0.63 \mathrm{~m}$ except for profile 5 shown in figure 13e. The maximum difference exceeds $6 \mathrm{~m}$ at places but attributed to the larger depth retrieval and proportion of area it estimated. Difference from L8 SSA are slightly larger, a fact that can be explained simply by the RMSE and bias estimation.

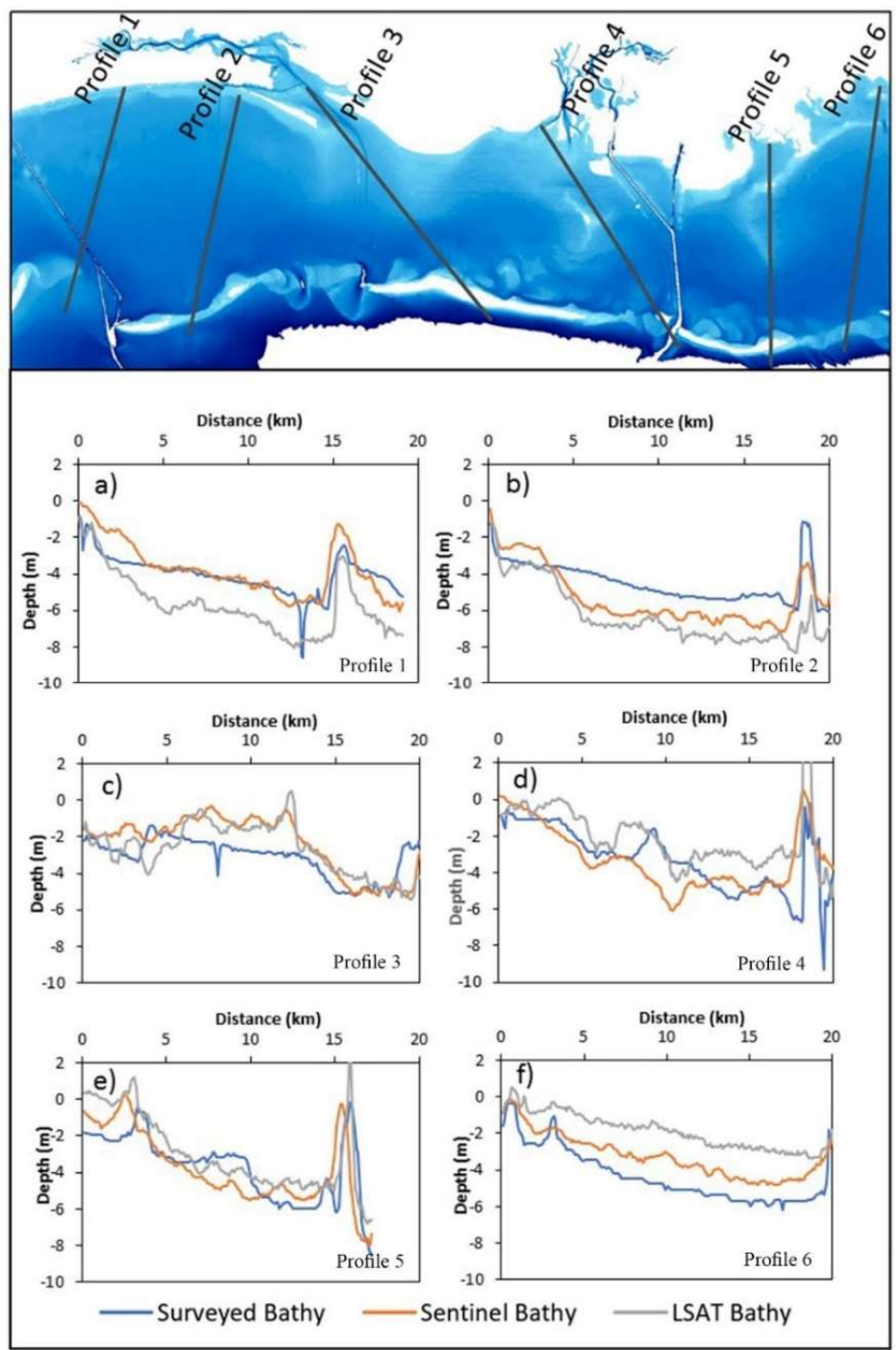

Figure 11. Longitudinal profile analysis of Mobile Bay bathymetry derived from Sentinel-2 MSI and Landsat 8 OLI images and comparison with the surveyed bathymetry obtained from NOAA's NGDC. 


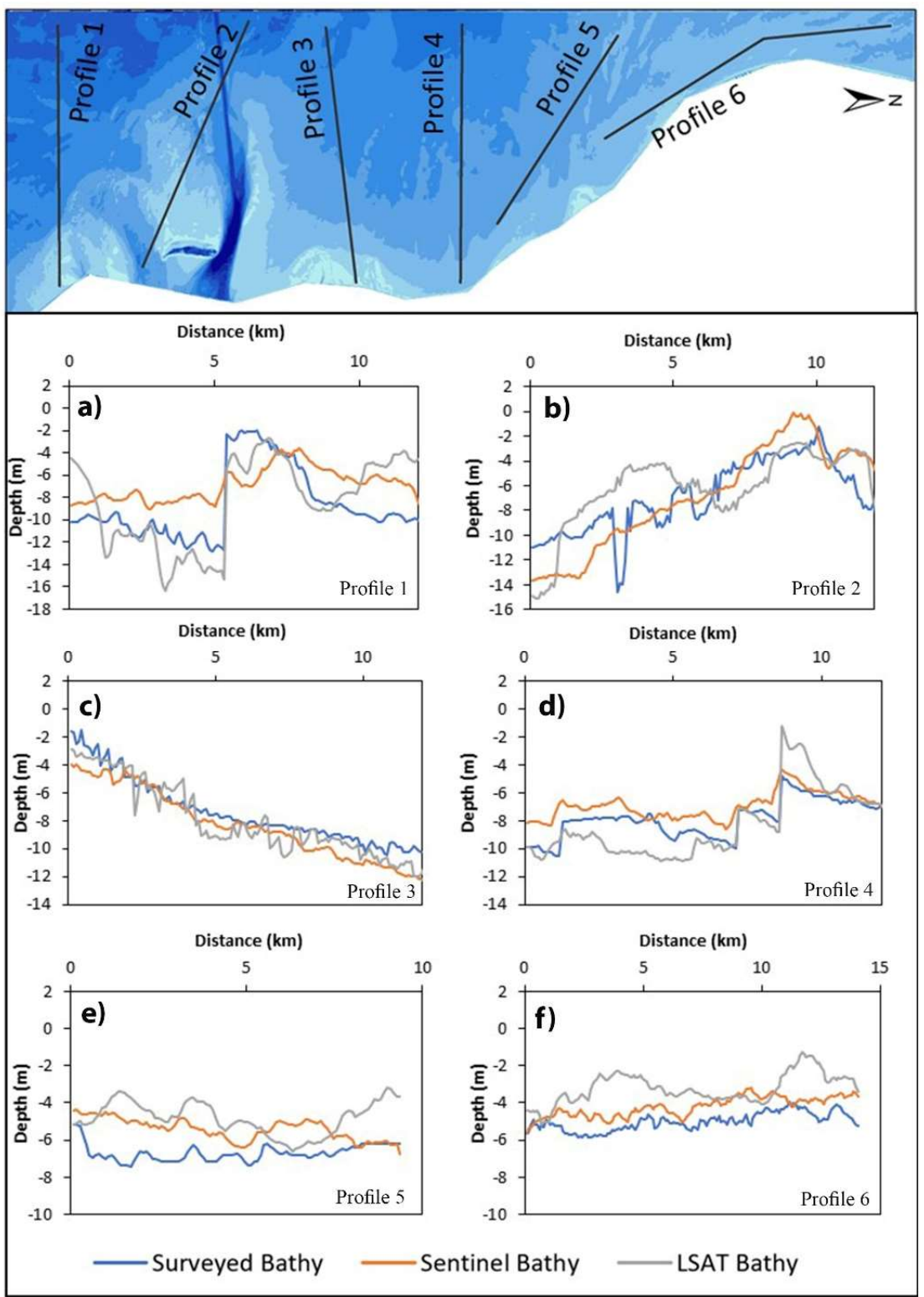

Figure 12. Longitudinal profile analysis of Tampa Bay bathymetry derived from Sentinel-2 MSI and Landsat 8 OLI images and comparison with the surveyed bathymetry obtained from NOAA's NGDC. 


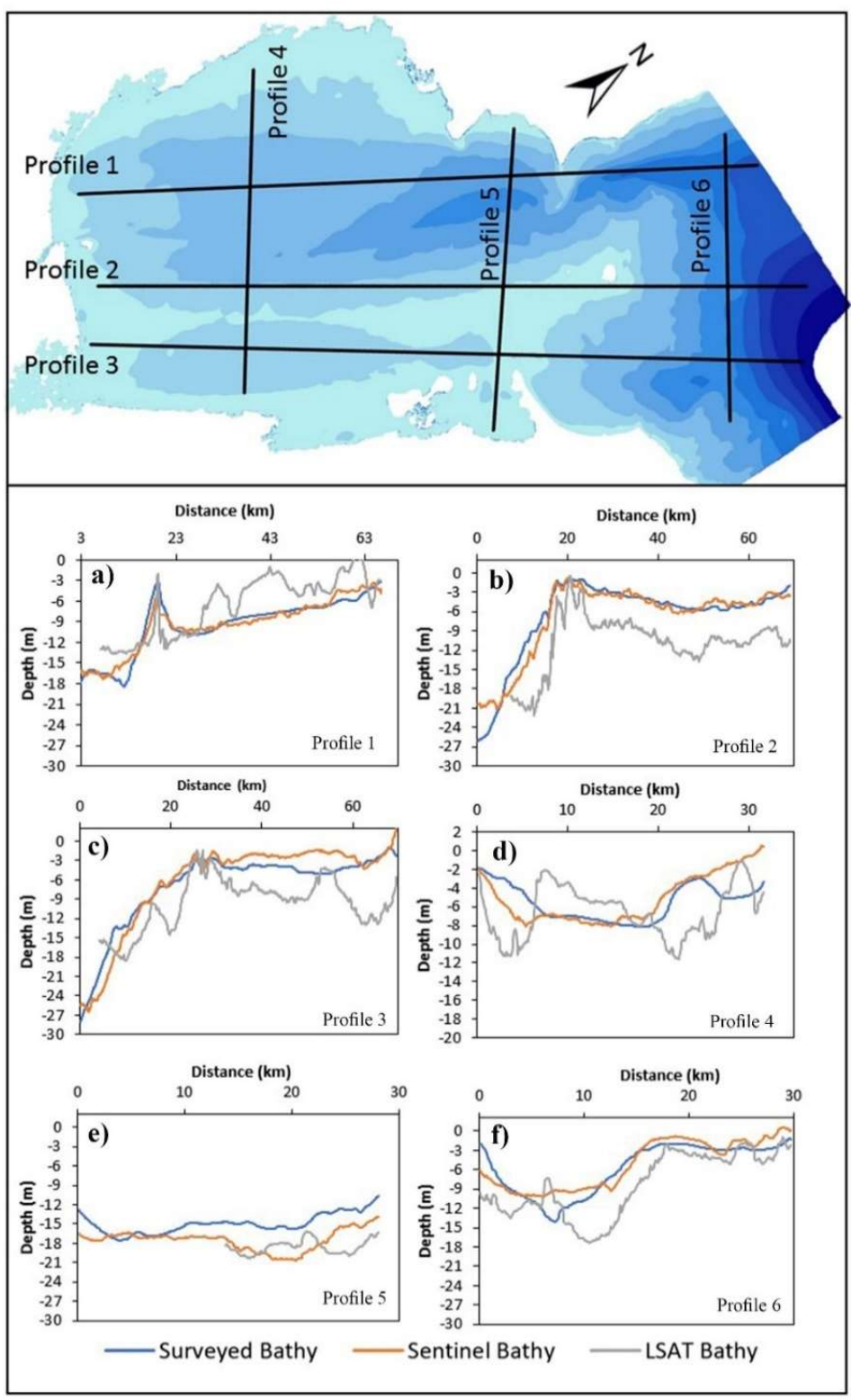

Figure 13. Longitudinal profile analysis of Lake Huron bathymetry derived from Sentinel-2 MSI and Landsat 8 OLI images and comparison with the surveyed bathymetry obtained from NOAA's NGDC.

\section{Conclusion}

The bathymetric map generated by S2 SSA and L8 SSA algorithms is by large effective in mapping bottom topography of Mobile Bay, Tampa Bay and Lake Huron, despite distinct differences in the morphometry and location. Inherent errors, smoothening and morphological variation happened for the time difference between the surveyed bathymetry and this study is not considered in our analysis. Therefore, it is reasonable to assume that if outliers were removed, the SSA algorithm can retrieve depths between 0 and $10 \mathrm{~m}$ for coastal areas, and up to $30 \mathrm{~m}$ for lake regions in optically clear waters. The value of RMSE ranges between $1.99 \mathrm{~m}$ (Lake Huron) and $2.80 \mathrm{~m}$ (Tampa Bay) for S2 SSA whereas the RMSE estimated from L8 SSA is much higher and ranges between $2.50 \mathrm{~m}$ (Tampa Bay) and $4.74 \mathrm{~m}$ (Lake Huron). Although there is no exact match with the observed profiles, it is clear that even if the SSA algorithm is used, the worst-case scenario is $3 \mathrm{~m}$ difference for coastal areas from Sentinel sensor. In order to validate the applicability of this method to other areas and development 
of regional bathymetric models, we plan to investigate ways of improving the current model by analyzing more images from different time periods, in particular to examine methods for addressing suspended sediment particles. Result of this study is a good first indication that the Sentinel-2 can be utilized for remotely sensed bathymetry extraction for coastal and lake areas and complement the data from survey sources.

Author Contributions: Conceptualization, Y.A. and D.J.; methodology, Y.A.; software, R.A.; validation, Y.A., D.J. and R.A.; formal analysis, Y.A.; investigation, Y.A.; resources, S.X.; writing-original draft preparation, Y.A., D.J., and S.X.; writing - review and editing, R.A.; supervision, R.A.; project administration, S.X.

Funding: This research received no external funding

Acknowledgments: Authors are thankful to NOAA's NGDC for providing freely available bathymetric DEMS; and NASA, USGS and ESA for access to the Landsat 8 and Sentinel-2 satellite imageries.

Conflicts of Interest: The authors declare no conflict of interest.

\section{References}

1. Cooper, J.; Navas, F. Natural bathymetric change as a control on century-scale shoreline behavior. Geology 2004, 32, 513-516.

2. Clarke, J.E.H. First wide-angle view of channelized turbidity currents links migrating cyclic steps to flow characteristics. Nature communications 2016, 7, 11896.

3. Simons, D.; Richardson, E. Resistance to flow in alluvial channels. Professional Paper 422-J, Washington DC. US Geological Survey 1966.

4. Brando, V.E.; Anstee, J.M.; Wettle, M.; Dekker, A.G.; Phinn, S.R.; Roelfsema, C. A physics based retrieval and quality assessment of bathymetry from suboptimal hyperspectral data. Remote Sensing of Environment 2009, 113, 755-770.

5. Pacheco, A.; Horta, J.; Loureiro, C.; Ferreira, Ó. Retrieval of nearshore bathymetry from Landsat 8 images: A tool for coastal monitoring in shallow waters. Remote Sensing of Environment 2015, 159, 102-116.

6. Maxwell, S.M.; Hazen, E.L.; Lewison, R.L.; Dunn, D.C.; Bailey, H.; Bograd, S.J.; Briscoe, D.K.; Fossette, S.; Hobday, A.J.; Bennett, M.; et al. Dynamic ocean management: Defining and conceptualizing real-time management of the ocean. Marine Policy 2015, 58, 42-50.

7. Kachelriess, D.; Wegmann, M.; Gollock, M.; Pettorelli, N. The application of remote sensing for marine protected area management. Ecological Indicators 2014, 36, 169-177.

8. Monteys, X.; Harris, P.; Caloca, S.; Cahalane, C. Spatial prediction of coastal bathymetry based on multispectral satellite imagery and multibeam data. Remote Sensing 2015, 7, 13782-13806.

9. Carron, M.J.; Vogt, P.R.; Jung, W.-Y. A proposed international long-term project to systematically map the world's ocean floors from beach to trench: GOMaP (Global Ocean Mapping Program). The International Hydrographic Review 2001, 2.

10. Lyzenga, D.R. Shallow-water bathymetry using combined lidar and passive multispectral scanner data. International Journal of Remote Sensing 1985, 6, 115-125.

11. Stumpf, R.P.; Holderied, K.; Sinclair, M. Determination of water depth with high-resolution satellite imagery over variable bottom types. Limnology and Oceanography 2003, 48, 547-556.

12. Doxani, G.; Papadopoulou, M.; Lafazani, P.; Pikridas, C.; Tsakiri-Strati, M. Shallow-water bathymetry over variable bottom types using multispectral Worldview-2 image. International Archives of the Photogrammetry, Remote Sensing and Spatial Information Sciences 2012, 39, 159-164. 
13. Eugenio, F.; Marcello, J.; Martin, J. High-resolution maps of bathymetry and benthic habitats in shallowwater environments using multispectral remote sensing imagery. IEEE Transactions on Geoscience and Remote Sensing 2015, 53, 3539-3549.

14. Sandwell, D.T.; Smith, W.H.; Gille, S.; Kappel, E.; Jayne, S.; Soofi, K.; Coakley, B.; Géli, L. Bathymetry from space: Rationale and requirements for a new, high-resolution altimetric mission. Comptes Rendus Geoscience 2006, 338, 1049-1062.

15. Dixon, T.H.; Naraghi, M.; McNutt, M.; Smith, S. Bathymetric prediction from Seasat altimeter data. Journal of Geophysical Research: Oceans 1983, 88, 1563-1571.

16. Lu, D.; Mausel, P.; Brondizio, E.; Moran, E. Assessment of atmospheric correction methods for Landsat TM data applicable to Amazon basin LBA research. International Journal of Remote Sensing 2002, 23, 2651-2671.

17. Jena, B.; Kurian, P.; Swain, D.; Tyagi, A.; Ravindra, R. Prediction of bathymetry from satellite altimeter based gravity in the Arabian Sea: Mapping of two unnamed deep seamounts. International Journal of Applied Earth Observation and Geoinformation 2012, 16, 1-4.

18. Guenther, G.C. Airborne lidar bathymetry. Digital elevation model technologies and applications: the DEM users manual 2007, 2, 253-320.

19. Bills, B.G.; Borsa, A.A.; Comstock, R.L. MISR-based passive optical bathymetry from orbit with few-cm level of accuracy on the Salar de Uyuni, Bolivia. Remote sensing of environment 2007, 107, 240-255.

20. Arsen, A.; Crétaux, J.-F.; Berge-Nguyen, M.; del Rio, R. Remote sensing-derived bathymetry of lake Poopó. Remote Sensing 2014, 6, 407-420.

21. Gao, J. Bathymetric mapping by means of remote sensing: methods, accuracy and limitations. Progress in Physical Geography 2009, 33, 103-116.

22. Leon, J.X.; Cohen, T. An improved bathymetric model for the modern and palaeo Lake Eyre. Geomorphology 2012, 173, 69-79.

23. Roy, D.P.; Wulder, M.; Loveland, T.R.; Woodcock, C.; Allen, R.; Anderson, M.; Helder, D.; Irons, J.; Johnson, D.; Kennedy, R.; et al. Landsat-8: Science and product vision for terrestrial global change research. Remote sensing of Environment 2014, 145, 154-172.

24. Pope, A.; Scambos, T.A.; Moussavi, M.; Tedesco, M.; Willis, M.; Shean, D.; Grigsby, S. Estimating supraglacial lake depth in West Greenland using Landsat 8 and comparison with other multispectral methods. The Cryosphere 2016, 10, 15. 